\title{
On the photoactivity of S-doped nanoporous carbons: Importance of surface chemistry and porosity
}

\author{
Teresa J. Bandosz*, Mykola Seredych \\ Department of Chemistry, The City College of New York, 160 Convent Ave, New York, NY 10031, USA
}

\section{A R T I C L E I N F O}

Article history:

Received 24 March 2014

Accepted 15 April 2014

Published 20 June 2014

\section{Keywords:}

Nanoporous carbons

Photoactivity

Oxidation

Surface chemistry

Oxygen reduction reaction (ORR)

Capacitive behavior

\begin{abstract}
A B S T R A C T
This minireview summarizes our recent findings on the photoactivity of S-doped nanoporous carbons. The materials were either synthesized from the sulfur-containing polymers or obtained by heat treatment of commercial carbon with hydrogen sulfide. Their surface was extensively characterized from the points of view of its surface chemistry, porosity, morphology, and electronic properties. The carbons showed enhanced activity towards oxidation of arsine and removal of dibenzothiophenes from model diesel fuel. The latter were oxidized to various oxygen containing intermediates and the cleavage of $\mathrm{C}-\mathrm{C}$ bonds in aromatic ring was detected when carbon with adsorbed species was exposed to UV or visible light. Irradiation resulted in generation of photocurrent in a broad range of wavelength. The presence of sulfur led to the reduction of oxygen and contributed to an increased capacitive performance. We link these effects to the presence of reduced sulfur in the small pores which enhances the dispersive interactions via inducing a positive charge to carbon atoms, to sulfur in oxygenated forms which contribute to Faradaic reactions and increase the polar interactions, and to the hydrophobicity of a surface in small pores where oxygen can be reduced by excited electrons from chromophoric-like sulfur containing groups.
\end{abstract}

(C) 2014, Dalian Institute of Chemical Physics, Chinese Academy of Sciences. Published by Elsevier B.V. All rights reserved.

\section{Introduction}

Nowadays, there is a need for a development of new functional materials being able to use/convert solar energy towards maintaining sustainable environment and decreasing costs of manufacturing and energy production. So far an inorganic [1-7] and organic [4,8-11] semiconducting materials have been widely investigated for this purpose with the goal to decrease the energy gap, decrease the costs of devices and to increase the efficiency of energy conversion. New emerging photoactive materials for this purpose are graphenes and graphene-based composites with semiconductors. The conducting properties of the former and the possibility of the latters' band gap modifications via introduction of defects were found of paramount importance [4,12-15].
Recently the presence of heteroatoms and the functionalities based on oxygen [16-19], nitrogen [18,20-22], and sulfur [23-28] in carbonaceous materials have attracted the attention of researchers addressing energy storage and conversion problems $[4,29]$. The photoactivity was found either in modified graphene [4,14,29-31] or in carbon dots [32-34]. It was demonstrated mainly in the photoluminescent behavior linked to a band gap alteration by the presence of heteroatoms [29-31] and the light absorbing nature of surface functional groups [30-33]. The conductive features of a carbon matrix were identified as an important asset.

From all heteroatoms present on the surface of nanoporous carbons, sulfur has been recently targeted in applications of these materials as efficient supercapacitors [23-25], oxygen reduction (ORR) catalysts $[27,28]$, solar energy harvesting me-

\footnotetext{
* Corresponding author. Tel: +1-212-6506017; Fax: +1-212-6506107; E-mail: tbandosz@ccny.cuny.edu 
dia [26], adsorbents of dibenzothiophenes from model diesel fuel [35-37], carbon dioxide capture media [38,39], or reactive ammonia adsorbents [40]. An excellent review on this topic has just been presented in Carbon journal [41]. One of our lines of research directly focuses on exploring the properties of these in the above mentioned applications [23-28,35-39,40,42], on understanding their photoactivity $[16,29,35,36,43]$, and on employing it to further enhance the performance in various applications at ambient conditions. Therefore, the objective of this minireview is to present a concise summary of our recent findings on these topics and to increase the awareness of carbon scientists to this new, exciting and not enough explored, feature of the old materials, porous carbons.

\section{Results and discussion}

\subsection{Intriguing extent of reactive adsorption on $S$-doped carbons}

Even though we have been working on carbons derived from carbonization of poly(sodium-4-styrenesulfonate) and poly(4-styrenesulfonic acid-co-maleic acid) sodium salt from the middle of the 90 s of the last century, the focus at that time was more on the specific porosity, morphology, and easiness of introduction of transition metals via cation exchange in the salts used [44-46] than on the surface chemistry of the carbon matrix. Using these carbons we found that there are some specific forces, like sulfur-sulfur bridges enhancing the adsorption of dibenzothiophenes from diesel fuel $[37,47,48]$. Some indication of dibenzothiophene oxidation was also found $[35-37,48]$. A real breakthrough in our approach occurred when these carbon were studied as adsorbents of arsine [42]. We found that on the carbon obtained from poly(sodium-4-styrenesulfonate) with a $3.7 \mathrm{~atm} \%$ sulfur incorporated to the carbon matrix and with a surface area of about $500 \mathrm{~m}^{2} / \mathrm{g}$, oxygen and sulfur-containing groups participated in arsine oxidation to arsenic tri- and pentoxide and/or in the formation of arsenic sulfides. We hypothesized that this occurred either via activation of oxygen or via a direct involvement of these groups in the reactions with arsine. That ability of heteroatom containing carbons was discussed by Boehm [49] and Strelko [50]. The latter researchers linked it to a decrease in the energy gap promoting the acceptance of electrons by oxygen present on the carbon surface. The oxidized sulfur species in the form of sulfonic acids increased the surface hydrophilicity of sulfur-containing carbons, causing that even though the experiments were run in dry gas the removal of arsine was enhanced via retention of small quantity of water from the environment. In moist conditions, with an increase in the humidity level, the preferential adsorption of water in the small pores blocked them from arsine penetration, which led to a decrease in the adsorptive performance. These oxidized carbons demonstrated higher adsorption capacities than commercial activated carbons modified with copper [51]. An increase in the reactivity of sulfur containing carbons due to the activity of superoxide ions was also found in the process of reactive adsorption of ammonia [40].

\subsection{Direct evidence of photocurrent generation}

The above discussed findings, ability of sulfur to alter the energy gap [50], and the fact that all experiments were carried out in visible light aimed our attention to a direct investigation of the photoactivity of sulfur doped carbons. In the efforts to formulate our hypothesis and to collect the preliminary data we evaluated the photoactivity of the nanoporous carbons modified with sulfur. Their surface areas were over $1000 \mathrm{~m}^{2} / \mathrm{g}$ with the volume of micropores $\sim 0.5 \mathrm{~cm}^{3} / \mathrm{g}$. The content of sulfur was 2.1 wt $\%$ (S-doped carbon B, BAX-1500 from Mead Westvaco treated with $\mathrm{H}_{2} \mathrm{~S}$ at $800{ }^{\circ} \mathrm{C}$ ) and $3.1 \mathrm{wt} \%$ (S-doped carbon $\mathrm{C}$, homemade carbon from poly(4-styrenesulfonic acid-co-maleic acid) sodium salt) [26,37,48]. One of these carbons was previously analyzed as an adsorbent of arsine [42] or ammonia [40] and very high activities for oxidation of these species was reported. The photocurrent generated vs. the wavelength, $\operatorname{PC}(\lambda)$, for different nanoporous carbon films is presented in Fig. 1(a). As seen, the sulfur containing carbons exhibited the photocurrent generation in a whole experimental
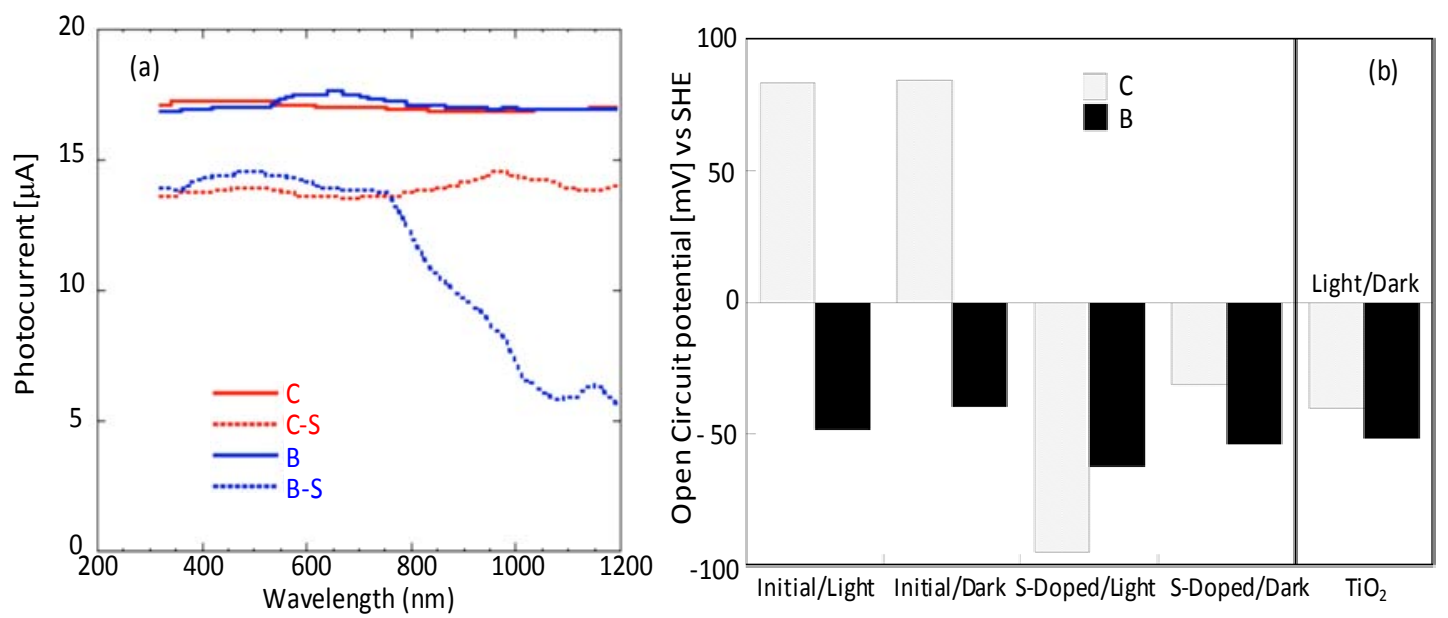

Fig. 1. (a) Photocurrent generated by the carbons studied; (b) Comparison of the open circuit potential. Reprinted with permission from Ref. [26]; copyright 2012, Elsevier. 
range of energy and their activity, although smaller than that for commercial silicone based photovoltaic cell [34,52], covers a very broad range of photons energy.

Figure 1(b) compares the open circuit potential (OCP) values in $0.5 \mathrm{~mol} / \mathrm{L} \mathrm{Na}_{2} \mathrm{SO}_{4}$ as an electrolyte. When the open circuit potential of the nanoporous carbon electrodes had been compared in dark and light, light exposure resulted in a significant increase in the potential in the negative range suggesting their high capability for oxidation reactions when exposed to visible light. That photoactivity was clearly demonstrated in the efficiency of methanol blue oxidation under visible light which was two times higher than that on titania [26].

\subsection{Oxidation of refractory sulfur compounds}

As mentioned above, sulfur doped nanoporous carbons were tested as reactive adsorbents of dibenzothiophene (DBT) and 4,6-dimethyldibenzothiophene (DMDBT) from model diesel fuel (MDF) and an enhancement in the reactivity towards oxidation of these refractory compounds was found [35-37,48]. To further test the oxidative properties of sulfurand phosphorous-doped carbons one commercial wood-based carbon WVA-1100 (Mead Westvaco, referred to as WVA) and poly(4-styrenesulfonic acid-co-maleic acid) sodium salt-derived carbon activated with phosphoric acid [36,53] (referred to as CP) were used as adsorbents of DBT and DMDBT from MDF. The adsorbents immersed in MDF were irradiated with UV, visible light (VL), and kept in dark (D) for three hours. Then the carbons were filtered and the qualitative analysis of the filtrates was performed using mass spectrometer Q-TRAP 4000. The compounds presented in Fig. 2 were identified [36].

The oxidative activity apparently depended on the irradiation conditions and the nature of the carbon surface (Table 1). Sulfur and phosphorous heteroatoms were identified as the most important features. The former was present only in CP in
Table 1

Compounds detected in the furan extracts. Reprinted with permission from Ref. [36]; copyright 2012 Elsevier.

\begin{tabular}{lcccccc}
\hline Product & CP-UV & WVA-UV & CP-VL & WVA-VL & CP-D & WVA-D \\
\hline A & D & D & D & D & D & D \\
B & D & D & D & D & D & D \\
C & D & D & D & D & D & D \\
D & ND & ND & ND & ND & D & D \\
E & D & D & D & D & ND & ND \\
F & D & D & D & D & ND & ND \\
G & D & ND & D & D & D & ND \\
H & D & D & D & D & ND & ND \\
I & ND & D & ND & ND & ND & ND \\
J & D & ND & ND & D & ND & ND \\
\hline
\end{tabular}

UV, Ultraviolet; VL, Visible light; D, Dark; D, detect, ND, not detected.

$0.5 \mathrm{~atm} \%$ and the latter was in $0.8 \mathrm{~atm} \%$ and $1.9 \mathrm{~atm} \%$ in WVA and $\mathrm{CP}$, respectively. The majority of sulfur was in thiophenic configurations, sulfides and thioethers. The similar products of DBT and DMDBT reactive adsorption were detected in the filtrates from both carbons suggesting that both sulfur and phosphorous functionalities contribute to photoactivity by decreasing the energy gap [50]. Generated holes participated in oxidation reactions.

To advance the findings, sulfur species were incorporated to BAX-1500 carbon (wood-based, Mead Westvaco; referred to as B) by treatment with $\mathrm{H}_{2} \mathrm{~S}$ at 650 and $800{ }^{\circ} \mathrm{C}[35,48]$. The modified carbons were referred to as B1S and B2S, respectively. Variations in a temperature were used to alter the speciation of sulfur compounds at the surface. The thermal mass profiles of relevant species detected in the gases during thermal analysis in helium are presented in Fig. 3. The carbons have similar contents of ash (about 2\%-3\%) so the effect of an inorganic phase on the photoactivity was excluded. The content of sulfur was $1.5 \mathrm{wt} \%$ and $2.1 \mathrm{wt} \%$ for B1S and B2S. The former carbon was found much more hydrophilic than the latter one. Even though the high content of sulfur in the B2S visibly increased
A<smiles>Cc1cccc2c1sc1c(C)cccc12</smiles>

C<smiles>O=S1c2ccccc2-c2ccccc21</smiles>

DBT-sulfoxide

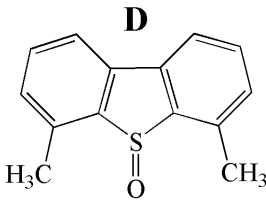

4,6-DMDBT-sulfoxide<smiles>O=S1(=O)c2ccccc2-c2ccccc21</smiles>

DBT-sulfone

$\mathbf{H}$<smiles>Cc1cccc2c(O)c(C=O)sc12</smiles>

F<smiles>Cc1cccc2c1S(=O)(=O)c1c(C)cccc1-2</smiles><smiles>O=CC1Sc2ccccc2C1O</smiles>

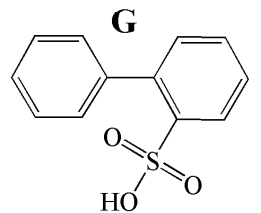

Biphenyl-2-sulfonic acid<smiles>Cc1cccc2c1SC(=O)C2=O</smiles>

3-Hydroxy-7-methyl-benzothiophene 3-Hydroxy-2-formylbenzothiophene 7-Methyl-benzothiophene -2-carbaldehyde

Fig. 2. Products of surface reactions. Reprinted with permission from Ref. [36]; copyright 2012, Elsevier. 


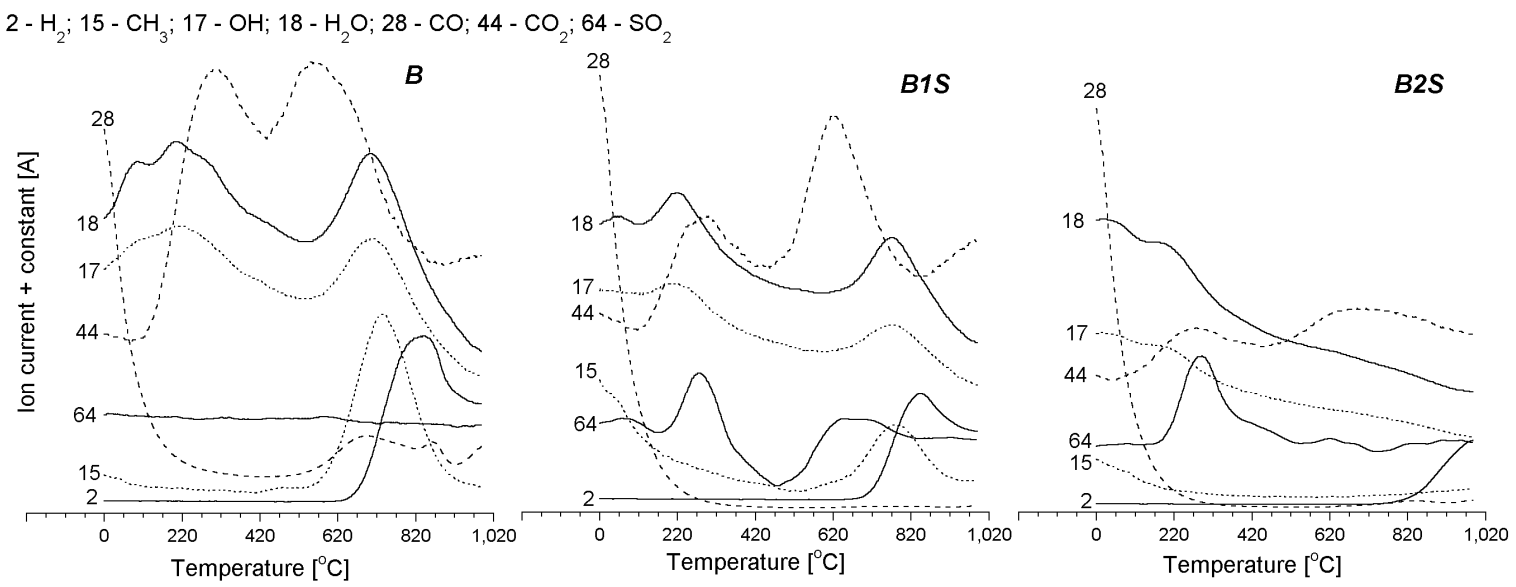

Fig. 3. MS patterns for the species desorbed from the surface of the carbon studied during thermal analysis in helium. Multiplication factor: MW $-2 \mathrm{x}$ 1; MW -15 × 500; MW - $17 \times 60$; MW -18 × 20; MW -28 × 3.5; MW -44 × 200; MW $-64 \times 5500$. Reprinted with permission from Ref. [35]; copyright 2013, Elsevier.

the adsorption of DBT and DMDBT and cumulative amount of sulfur adsorbed was $37.9,25.5$, and $22.5 \mathrm{mg} / \mathrm{g}$ for B2S, B1S, and $\mathrm{B}$, respectively, the extent of oxidation was the highest for the B1S as seen from Table 2. The compounds designated by letters are the same as those in Fig. 2. That extent of oxidation, contrary to previous study [36], was evaluated by exposing filtered carbons with adsorbed DBT and DMDBT to VL, UV and kept in dark, followed by extraction of the surface reaction products with furan. The changes in surface chemistry of the initial carbons exposed to the same irradiation levels as those for filtered carbons were also investigated and B1S was found as the most affected one. This was demonstrated by a visible increase in the number of acidic groups detected on the surface. The efficient oxidation of DBT and DMDBT to various compounds, even to 7-methyl-benzothiophene-2,3-dione detected only on B1S, regardless the level of irradiation, was linked to the presence of sulfur in specific configurations and also the ability of carbon to retain water [35]. It was proposed that when carbons with the semiconducting properties are exposed to irradiation, electrons and holes are formed. The latter contribute to the formation of active radicals either from water of $\mathrm{OH}$ groups of carbons and the photoinduced electrons contribute to oxygen reduction reactions resulting in the formation of superoxide ions $\mathrm{O}_{2}{ }^{-}$ $[16,54]$. Both oxygen radicals and superoxide ions are attacking DBT and DMDBT adsorbed in the small pores. For this processes some conductive properties of the graphene layers of carbons are important since they help with the electron transfer through the carbon matrix. The important role of sulfur in this mechanism is in decreasing the energy gap [50], and in bringing the positive charge to the carbon atoms in vicinity of sulfur in thiophenic configurations [23,24,27,28]. Those positively charged centers are the centers for oxygen reduction and thus the efficiency of oxidation increases.

To increase the amount of sulfur in thiophenic configurations, which we thought decreased the energy gap in the S-doped carbons, the composite of the poly(4-styrenesulfonic acid-co-maleic acid) sodium salt-derived carbons with graphene were synthesized [55]. The materials were tested in exactly the same conditions as those for B, B1S, and B2S carbons addressed above [35]. The results are collected in Table 2. As seen, the addition of graphene increased the efficiency of oxidation and more oxidized species were detected in the extract from the composites. The addition of $2 \mathrm{wt} \%$ graphene decreased the oxygen content of about $30 \%$ and increased four times the amount of sulfur. Moreover, the conductivity of the composite increased four times compared to that of the carbon from polymer (CPS). Exposure of the initial materials to VL, UV, and keeping them dark environment resulted in changes in surface chemistry indicating the reducing effect of the graphene phase on the sulfur species states of oxidation (Fig. 4). That graphene phase limited the release of sulfur-containing gases during the carbonization and thus more sulfur was in-

Table 2

Speciation of the products detected in the extract from the samples' surface using mass spectrometer [35,55].

\begin{tabular}{|c|c|c|c|c|c|c|c|c|c|c|c|c|c|c|c|}
\hline Product & B-D & B-UV & B-VL & B1S-D & B1S-UV & B1S-VL & B2S-D & B2S-UV & B2S-VL & CPS-D & CPS-UV & CPS-VL & CPSGr-D & CPSGr-UV & CPSGr-VL \\
\hline A & + & + & + & + & + & + & + & + & + & + & + & + & + & + & + \\
\hline B & + & + & + & + & + & + & + & + & + & + & + & + & + & + & + \\
\hline C & + & + & + & + & + & + & + & + & + & + & + & + & + & + & + \\
\hline D & + & + & + & + & + & & + & + & & & & & & & \\
\hline $\mathbf{E}$ & & + & + & + & + & + & & + & + & & + & + & + & + & + \\
\hline $\mathbf{F}$ & & + & & + & + & + & & + & + & & & & & & \\
\hline $\mathbf{G}$ & & + & + & & + & + & & + & + & & + & + & & + & + \\
\hline $\mathbf{H}$ & & & & & & + & & + & & & + & + & & & + \\
\hline I & & & & & & & & + & + & & & + & & & \\
\hline J & & & & & + & + & & & & & & & & + & + \\
\hline
\end{tabular}



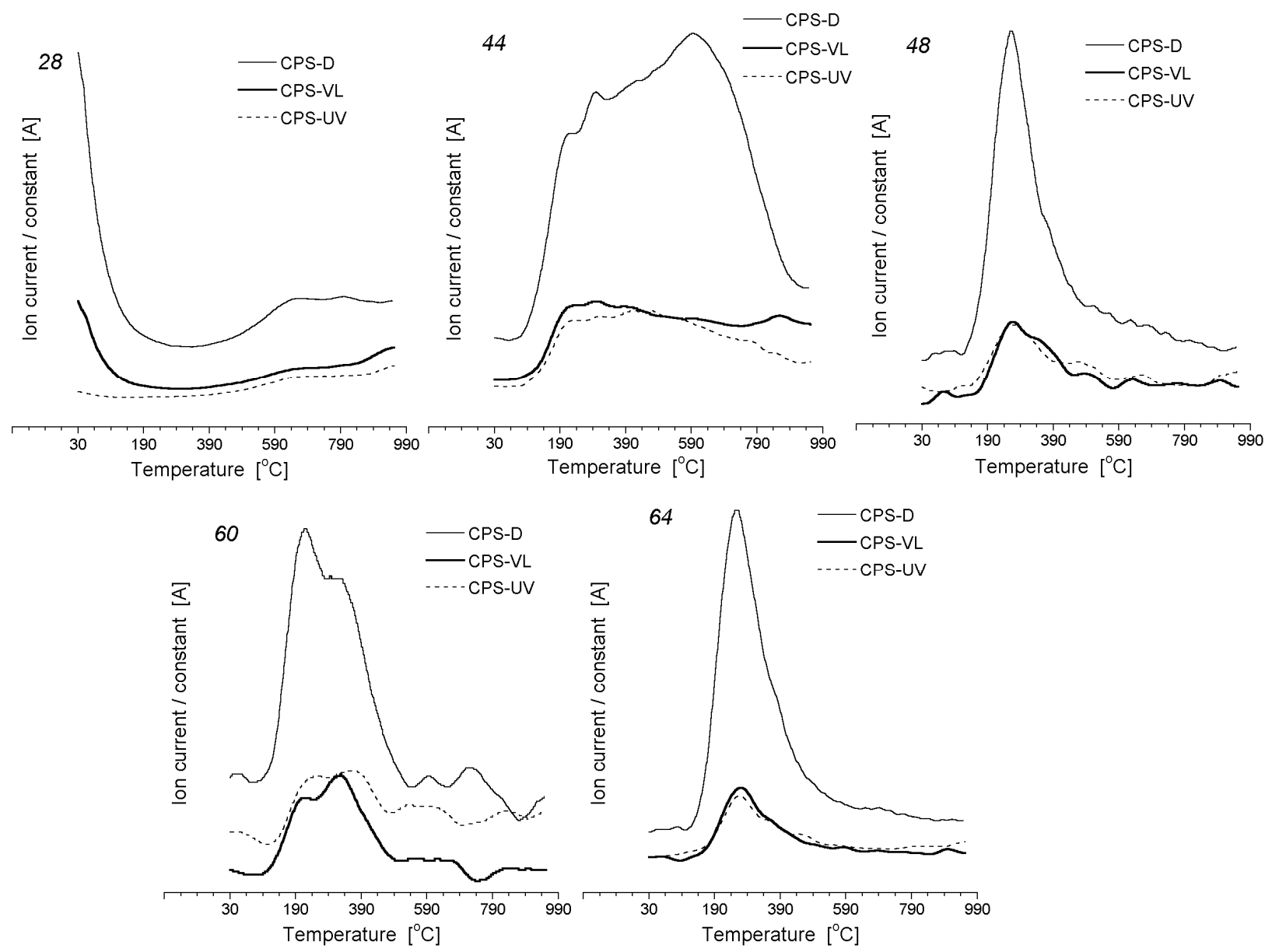

Fig. 4. The MS patterns for the initial polymer-derived carbon as obtained (D) and after expose in UV and VL. Reprinted with permission from Ref. [55]; copyright 2013, Elsevier.

troduced to the carbon matrix, especially in thiophenic configurations owing to a reducing environment. As indicated above, this resulted in the attraction of more superoxide ions and thus in increasing the efficiency of surface oxidation reactions. This efficiency was also enhanced owing to the fast electron transfer through the conductive graphene phase.

\subsection{Effect of irradiation on the capacitive performance}

Nanoporous carbons are known as promising materials for supercapacitors [17]. The charge can be stored in their developed pore system mainly following the Electrical Double Layer mechanism. Another process increasing the capacitance are Faradaic reactions on the heteroatom containing functional groups of a carbon surface [18-25]. For charge storage the presence of pores of sizes similar to the ions $(0.7 \mathrm{~nm})$ [56-58], high surface conductivity [59,60] and wettability [59-61] are of paramount importance.

The capacitive behavior of poly(sodium-4-styrenesulfonate) derived carbon [43] (referred to as PSC) was studied in sodium sulfate or sulfuric acid either in dark (D) or under simulated solar irradiation (L). To study the effect of oxygen in the system, the experiments were carried out in the electrolytes with dissolved oxygen (EXP A) and without oxygen in the electro- lytes (EXP B). Twenty CV curves were recorded for each electrolyte to check its stability and the effect of the applied conditions on the capacitance. Comparison of the specific capacitance values measured in both electrolytes after first (CV1) and 20th (CV20) cycles at various conditions is presented in Fig. 5. The values of the open circuit potentials are summarized in Fig. 6. In sulfuric acid the presence of oxygen and visible light irradiation resulted in $60 \%$ higher capacitance compared to the system without oxygen. On the other hand, the opposite effect was found in $\mathrm{Na}_{2} \mathrm{SO}_{4}$ and the capacitance was $50 \%$ lower with dissolved oxygen than without oxygen in the electrolyte. 20 cycles in sulfuric acid with oxygen in the system under visible-light irradiation resulted in six-fold increase in the capacitance which was $30 \%$ higher compared to that measured in the dark after 20 cycles. In the absence of oxygen, visible light has a negative effect on the capacitive performance indicating the importance of oxygen activation photoinduced reactions. The electrochemical capacitance values measured in sodium sulfate were much smaller than those in sulfuric acid owing to the lack of the pseudocapacitive contribution in the former system. After 20 cycles in the presence of light or in dark with oxygen in the system, the capacitance increased significantly. Photoactivity seemed not to affect the performance in sodium sulfate.

In all cases, the OCP had positive values (Fig. 6) showing 


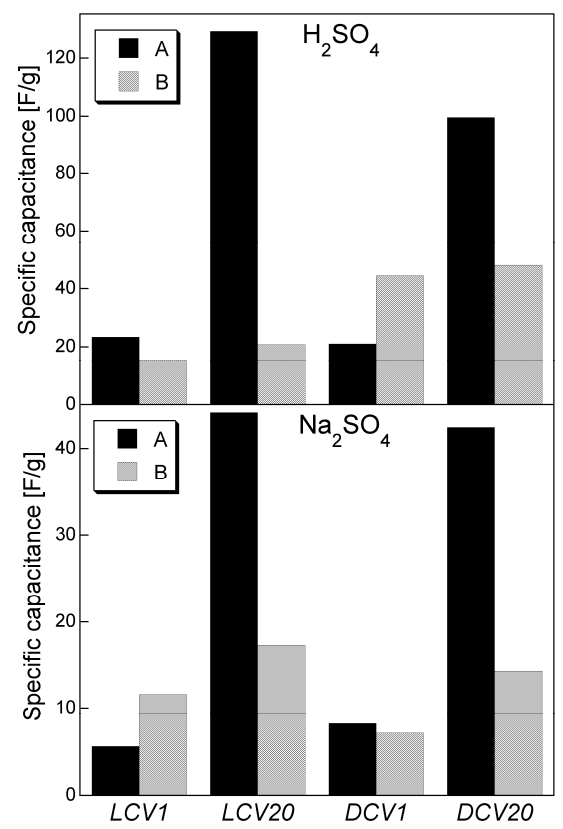

Fig. 5. The specific capacitance for all experimental conditions. Reprinted with permission from Ref. [43]; copyright 2014, WILEY-VCH.

that the carbon material studied worked as a cathode. In sulfuric acid in the systems exposure to light resulted in slightly higher values of OCP in both conditions with and without oxygen in comparison to those measured in dark. On the other hand, in neutral electrolyte, visible light decreased the reducing potential of the electrode. This was linked to an increase in the extent of oxidation reactions promoted by irradiation.

The photoactivity and the observed enhancement in the capacitance, especially in sulfuric acid, were linked to specific surface chemistry and its interactions with the electrolytes. The results of XPS study are summarized in Table 3. After exposure to $\mathrm{VL}$, in oxygen or without, the content of oxygen on the surface increased twice for the samples run in sodium sulfate (from over $4 \mathrm{~atm} \%$ to over $8 \mathrm{~atm} \%$ ). The effect in sulfuric acid was almost negligible. On the other hand, the content of sulfur was more or less on the constant level of about 1.2-1.4 atm\%. Interestingly when the experiments were run in sodium sulfate without and with oxygen in the system the contribution of

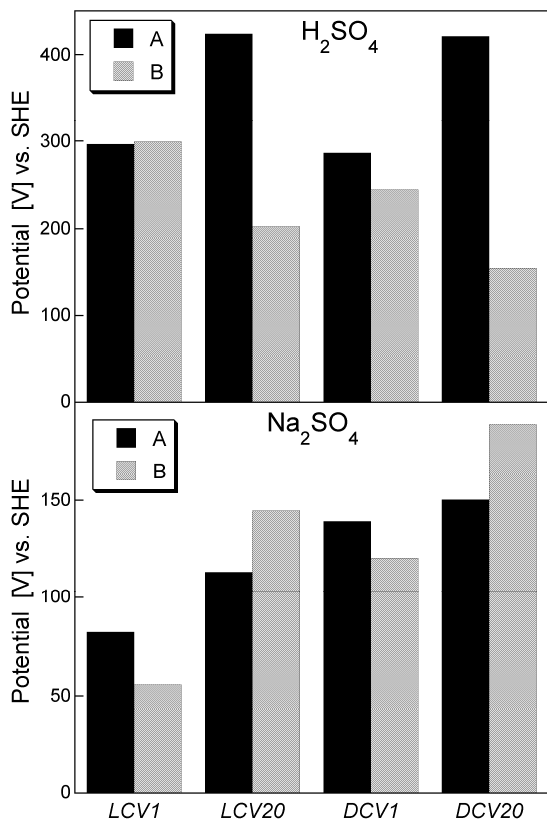

Fig. 6. The comparison of the open circuit potential for all experimental conditions. Reprinted with permission from Ref. [43]; copyright 2014, WILEY-VCH.

epoxy groups, phenols or ethers increased $52 \%$ and $22 \%$ respectively, showing more changes in oxygen depleted solution. In sulfuric acid the increase in these oxygen groups was slightly higher ( $4 \mathrm{~atm} \%$ ) when oxygen was in the system than without it (38 atm\%). Sulfur species were initially predominant in their reduced form ( $\mathrm{SH}$, thioethers, bisulfides) but after exposure to light the contribution of sulfoxides/sulfones visibly increased in both electrolytes, regardless the oxygen content.

An important question to answer was that about the source of oxygen incorporated to the carbon matrix, especially in the oxygen-depleted electrolytes. Based on the results obtained and those published in the literature $[27,28,43]$, it was hypothesized that owing to that fact that sulfur enhances ORR reaction $\mathrm{H}_{2} \mathrm{O}_{2}$ was formed and oxidized the electrodes. But this process could only happen when oxygen was present in the system. Oxidation could "activate carbon" and open more pores where charge could be stored via EDLC mechanism. Support for that was in visible broad ORR peaks on the $\mathrm{CV}$ curves at the poten-

Table 3

Chemical states of C, $\mathrm{O}$, and $\mathrm{S}$ atoms with a surface concentration (in atomic concentration \%) and their binding energy (eV in parenthesis). Reprinted with permission from Ref. [43]; copyright 2014, WILEY-VCH.

\begin{tabular}{|c|c|c|c|c|c|c|c|c|}
\hline Sample & $\mathrm{C}-(\mathrm{C}, \mathrm{S})$ & $\mathrm{C}-\mathrm{O}$ & $\mathrm{C}=\mathrm{O}$ & $\mathrm{C}-\mathrm{F}$ & $\begin{array}{c}\text { O-I } \\
(\mathrm{O}=\mathrm{C} / \text { or } \mathrm{O}=\mathrm{S}) \\
\end{array}$ & $\begin{array}{c}\text { O-II } \\
(\mathrm{O}-\mathrm{C} / \text { or O-S })\end{array}$ & $\mathrm{R}-\mathrm{SH}$ & $\begin{array}{l}\mathrm{R}_{2}-\mathrm{S}=\mathrm{O} / \\
\mathrm{R}-\mathrm{SO}_{2}-\mathrm{R}\end{array}$ \\
\hline PSC & $\begin{array}{c}43.29 \\
(284.3)\end{array}$ & $\begin{array}{c}14.42 \\
(286.0)\end{array}$ & $\begin{array}{c}4.66 \\
(287.6)\end{array}$ & $\begin{array}{c}12.70 \\
(290.3)\end{array}$ & $\begin{array}{c}3.57 \\
(532.0)\end{array}$ & $\begin{array}{c}0.47 \\
(534.0)\end{array}$ & $\begin{array}{c}0.88 \\
(163.6)\end{array}$ & $\begin{array}{c}0.40 \\
(167.7)\end{array}$ \\
\hline PSC- $\mathrm{Na}_{2} \mathrm{SO}_{4}$-LCV20A & $\begin{array}{c}44.64 \\
(284.4)\end{array}$ & $\begin{array}{c}15.11 \\
(286.0)\end{array}$ & $\begin{array}{c}5.56 \\
(287.6)\end{array}$ & $\begin{array}{c}11.46 \\
(290.2)\end{array}$ & $\begin{array}{c}5.90 \\
(532.2)\end{array}$ & $\begin{array}{c}1.58 \\
(533.3)\end{array}$ & $\begin{array}{c}0.71 \\
(163.6)\end{array}$ & $\begin{array}{c}0.72 \\
(168.0)\end{array}$ \\
\hline PSC-Na $\mathrm{SO}_{4}$-LCV20B & $\begin{array}{c}43.43 \\
(284.5)\end{array}$ & $\begin{array}{c}14.92 \\
(286.1)\end{array}$ & $\begin{array}{c}5.62 \\
(287.6)\end{array}$ & $\begin{array}{c}11.17 \\
(290.3)\end{array}$ & $\begin{array}{c}4.06 \\
(532.0)\end{array}$ & $\begin{array}{c}4.48 \\
(533.5)\end{array}$ & $\begin{array}{c}0.64 \\
(163.6)\end{array}$ & $\begin{array}{c}0.54 \\
(167.9)\end{array}$ \\
\hline $\mathrm{PSC}-\mathrm{H}_{2} \mathrm{SO}_{4}-\mathrm{LCV} 2 \mathrm{AA}$ & $\begin{array}{c}45.67 \\
(284.4)\end{array}$ & $\begin{array}{c}14.22 \\
(286.0)\end{array}$ & $\begin{array}{c}4.88 \\
(287.6)\end{array}$ & $\begin{array}{c}12.17 \\
(290.3)\end{array}$ & $\begin{array}{c}2.99 \\
(531.5)\end{array}$ & $\begin{array}{c}2.39 \\
(533.1)\end{array}$ & $\begin{array}{c}0.73 \\
(163.6)\end{array}$ & $\begin{array}{c}0.69 \\
(168.1)\end{array}$ \\
\hline $\mathrm{PSC}-\mathrm{H}_{2} \mathrm{SO}_{4}-\mathrm{LCV} 20 \mathrm{~B}$ & $\begin{array}{c}44.36 \\
(284.4)\end{array}$ & $\begin{array}{c}14.20 \\
(286.0)\end{array}$ & $\begin{array}{c}4.87 \\
(287.5)\end{array}$ & $\begin{array}{c}12.68 \\
(290.3)\end{array}$ & $\begin{array}{c}2.67 \\
(531.6)\end{array}$ & $\begin{array}{c}2.08 \\
(533.1)\end{array}$ & $\begin{array}{c}0.73 \\
(163.6)\end{array}$ & $\begin{array}{c}0.52 \\
(167.9)\end{array}$ \\
\hline
\end{tabular}


tial between $0.1-0.4 \mathrm{~V}$ vs. SHE. Formed sulfoxides and sulfones underwent Faradaic reactions and increased the pseudocapacitance in sulfuric acid. Since the expected effect of photoactivity is generation of the electrons, those electrons could have a reducing effect on the carbons surface and could, on the other hand, enhance Faradaic reaction on the surface as proposed below [43].

In the presence of oxygen:

$$
\begin{aligned}
& \mathrm{O}_{\mathrm{S}}^{\mathrm{II}}+\overline{\mathrm{e}} \longrightarrow \mathrm{O}_{\mathrm{S}}^{\mathrm{O}^{\bullet}-} \\
& \mathrm{O}_{\mathrm{S}}^{\mathrm{O}^{*}}+\mathrm{O}_{2} \longrightarrow \mathrm{O}_{\mathrm{S}}^{\mathrm{O}}-\mathrm{O}_{2}^{\cdot} \\
& \mathrm{O}_{\mathrm{S}}^{\mathrm{O}}-\mathrm{O}_{2}^{\cdot}+\overline{\mathrm{e}}+2 \mathrm{H}^{+} \longrightarrow \mathrm{S}_{\mathrm{S}}^{\mathrm{O}}+\mathrm{H}_{2} \mathrm{O}_{2}
\end{aligned}
$$

And without oxygen:

$$
\begin{aligned}
& {\stackrel{\mathrm{O}}{\mathrm{S}^{-}}}^{-}+\mathrm{H}^{+} \longrightarrow \stackrel{\mathrm{HO}_{\mathrm{S}}^{*}}{\mathrm{O}} \\
& \mathrm{O}_{\mathrm{S}}^{\mathrm{O}^{-}}+\mathrm{H}_{2} \mathrm{O} \longrightarrow \mathrm{OH}_{\mathrm{S}}^{\mathrm{H}}+\mathrm{OH}^{-}
\end{aligned}
$$

As a source of an oxidant in the absence of oxygen in the system the holes were proposed. There was an indication on the CV curves that they can contribute to oxygen evaluation reaction. That formed oxygen could undergo ORR reactions and thus participate in surface oxidation. That effect was especially important in a neutral electrolyte. In this system, since $\mathrm{H}^{+}$is limited and photogenerated electrons could not participate extensively in the above presented reactions, the electrons reduced sulfur in sulfate ions and thus oxygen was provided to the system, which resulted in an extensive surface oxidation. Photogenerated holes on the other hand oxidized water and this increased the extent of surface oxidation of the carbon electrode.

\section{Conclusions}

The results addressed in this minireview underline the new and unexplored phenomenon found on the surface of sulfur containing carbons - their photoactivity. That photoactivity was directly demonstrated by generation of photocurrent when the carbons were exposed to a broad range of irradiation [26]. Indirect demonstration of this exciting feature was in the efficient oxidation of methylene blue [26] and oxidation of refractory sulfur compounds present in model diesel fuel. In the latter the extensive oxidation with incorporation of oxygen and the cleavage of $\mathrm{C}-\mathrm{C}$ bonds was found upon exposure to visible light $[35,36,55]$. That photoactivity was also found as promoting oxygen reduction reactions and thus increasing the electrochemical capacitance when carbons are used as supercapacitors either in neutral or acidic electrolytes [43]. Photoactivity of nanoporous carbons is an important feature worthy of exploration and testing in various applications. Taking into account a developed surface area of carbons, which increases the contact with the species distributed/retained in the pore system and their black nature resulting in the absorption of practically all spectra of visible radiation, these materials might have promising potential in solar energy harvesting and applications in such fields as catalysis, energy conversions and storage. The challenges are in the modifications of the surface leading to the stable materials and in optimization of the photocurrent generated in the pore system.

\section{References}

[1] Wang D, Hisatomi T, Takata T, Pan C, Katayama M, Kubota J, Domen K. Angew Chem Int Ed, 2013, 52: 11252; Angew Chem, 2013, 125: 11462

[2] Maeda K, Lu D, Domen K. Chem Eur J, 2013, 19: 4986

[3] Maeda K. Chem Commun, 2013, 49: 8404

[4] Li C J, Xu G R, Zhang B H, Gong J R. Appl Catal B, 2012, 115-116: 201

[5] Kudo A, Kato H. Chem Phys Lett, 2000, 331: 373

[6] Yan H J, Yang J H, Ma G J, Wu G P, Zong X, Lei Z B, Shi J Y, Li C. J Catal, 2009, 266: 165

[7] Xie G C, Zhang K, Guo B D, Liu Q, Fang L, Gong J R. Adv Mater, 2013, 25: 3820

[8] Grätzel M.J Photochem Photobiol A, 2004, 164: 3

[9] Maeda K, Teramura K, Saito N, Inoue Y, Kobayashi H, Domen K. Pure Appl Chem, 2006, 78: 2267

[10] Ishikawa A, Takata T, Matsumura T, Kondo J N, Hara M, Kobayashi H, Domen K. J Phys Chem B, 2004, 108: 2637

[11] Hitoki G, Takata T, Kondo J N, Hara M, Kobayashi H, Domen K. Chem Commun, 2002: 1698

[12] Islam S M Z, Gayen T, Seredych M, Mabayoje O, Shi L Y, Bandosz T J, Alfano R R.J Appl Phys, 2013, 114: 043522/1

[13] Islam S M Z, Gayen T, Tint N, Shi L Y, Ebrahim A M, Seredych M, Bandosz T J,Alfano R. J Photonics Energy, 2014, 4: 043098

[14] Ng Y H, Iwase A, Kudo A, Amal R.J Phys Chem Lett, 2010, 1: 2607

\section{Graphical Abstract}

Chin. J. Catal., 2014, 35: 807-814 doi: 10.1016/S1872-2067(14)60100-5

On the photoactivity of $S$-doped nanoporous carbons: Importance of surface chemistry and porosity

Teresa J. Bandosz*, Mykola Seredych

The City College of New York, USA

The photoactivity of nanoporous carbons in visible light was demonstrated by generation of photocurrent and by the efficient oxidation of methylene blue and oxidation of refractory sulfur compounds present in model diesel fuel.

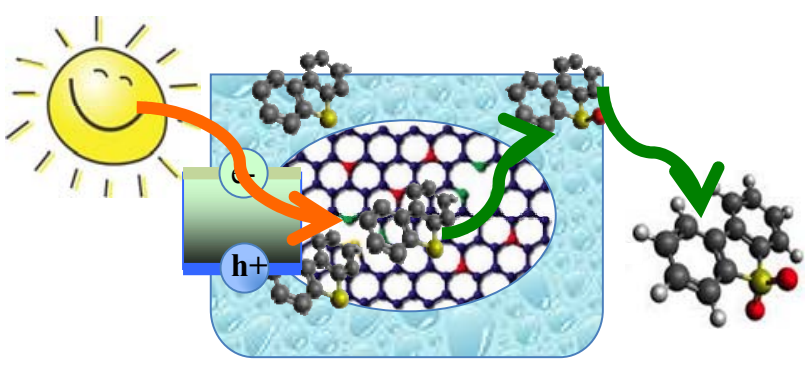


[15] Min S X, Lu G X.J Phys Chem C, 2011, 115: 13938

[16] Velasco L F, Maurino V, Laurenti E, Ania C. Appl Catal A, 2013, 453: 310

[17] Pandolfo A G, Hollenkamp A F. J Power Sour, 2006, 157: 11

[18] Hulicova-Jurcakova D, Seredych M, Lu G Q Bandosz T J. Adv Funct Mater, 2009, 19: 438

[19] Andreas H A, Conway B E. Electrochim Acta, 2006, 51: 6510

[20] Seredych M, Hulicova-Jurcakova D, Lu G Q, Bandosz T J. Carbon, 2008, 46: 1475

[21] Hulicova D, Kodama M, Hatori H. Chem Mater, 2006, 18: 2318

[22] Wang D W, Li F, Yin L C, Lu X, Chen Z G, Gentle I R, Lu G Q, Cheng H M. Chem Eur J, 2012, 18: 5345

[23] Seredych M, Bandosz T J. J Mater Chem A, 2013, 1: 11717

[24] Seredych M, Singh K, Bandosz T J. Electroanalysis, 2014, 26: 109

[25] Zhao X C, Zhang Q, Chen C M, Zhang B S, Reiche S, Wang A Q, Zhang T, Schlogl R, Su D S. Nano Energy, 2012, 1: 624

[26] Bandosz T J, Matos J, Seredych M, Islam S M Z, Alfano R. Appl Catal A, 2012, 445-446: 159

[27] Liang J, Jiao Y, Jaroniec M, Qiao S Z. Angew Chem Int Ed, 2012, 51: 1; Angew Chem, 2012, 124: 11664

[28] Seredych M, Bandosz T J. Carbon, 2014, 66: 227

[29] Han S, Wu D Q, Li S, Zhang F, Feng X L. Adv Mater, 2014, 26: 849

[30] Eda G, Lin Y Y, Mattevi C, Yamaguchi H, Chen H A, Chen I S, Chen C W, Chhowalla M. Adv Mater, 2010, 22: 505

[31] Shang J Z, Ma L, Li J W, Ai W, Yu T, Gurzadyan G G. Sci Rep, 2012, 2: 792

[32] Hola K, Bourlinos A B, Kozak O, Berka K, Siskova K M, Havrdova M, Tucek J, Safarova K, Otyepka M, Giannelis E P, Zboril R. Carbon, 2014, 70: 279

[33] Fan R J, Sun Q, Zhang L, Zhang Y, Lu A H. Carbon, 2014, 71: 87

[34] Baranauskas V, Tosin M C, Ceragioli H J, Zhao J G, Peterlevitz A C, Durrant S F. Phys Stat Sol A, 2000, 182: 395

[35] Seredych M, Messali L, Bandosz T J. Carbon, 2013, 62: 356

[36] Seredych M, Bandosz T J. Fuel, 2013, 108: 846

[37] Seredych M, Khine M, Bandosz T J. ChemSusChem, 2011, 4: 139

[38] Seema H, Kemp K C, Le N H, Park S W, Chandra V, Lee J W, Kim K S.
Carbon, 2014, 66: 320

[39] Seredych M, Jagiello J, Bandosz T J. Carbon, 2014, DOI: 10.1016/ j.carbon.2014.03.024

[40] Petit C, Kante K, Bandosz T J. Carbon, 2010, 48: 654

[41] Kicinski W, Szala M, Bystrzejewski M. Carbon, 2014, 68: 1

[42] Petit C, Peterson G W, Mahle J, Bandosz T J. Carbon, 2010, 48: 1779

[43] Singh K, Seredych M, Rodriguez-Castellon E, Bandosz T J. ChemElectroChem, 2014, 1: 565

[44] Putyera K, Jagiello J, Bandosz T J, Schwarz J A. Carbon, 1995, 33 1047

[45] Schwarz J A, Putyera K, Jagiello J, Bandosz T J. US Patent 5614460. 1997

[46] Hines D, Bagreev A, Bandosz T J. Langmuir, 2004, 20: 3388

[47] Ania C 0, Bandosz T J. Langmuir, 2005, 21: 7752

[48] Seredych M, Bandosz T J. Appl Catal B, 2011, 106: 133

[49] Stöhr B, Boehm H P, Schlögl R. Carbon, 1991, 29: 707

[50] Strelko V V, Kuts V S, Thrower P A. Carbon, 2000, 38: 1499

[51] Haacke G, Brien J S, Burkhard H. J Electrochem Soc, 1988, 135: 715

[52] Navarro Yerga R M, Alvarez-Galvan M C, Del Valle F, Villoria de la Mano J A, Fierro J L G. ChemSusChem, 2009, 2: 471

[53] Seredych M, Wu C T, Brender P, Ania C 0, Vix-Guterl C, Bandosz T J. Fuel, 2012, 92: 318

[54] Velasco L F, Maurino V, Laurenti E, Fonseca I M, Lima J C, Ania C O. Appl Catal A, 2013, 452: 1

[55] Seredych M, Bandosz T J. Appl Catal B, 2014, 147: 842

[56] Salitra G, Soffer A, Eliad L, Cohen Y, Aurbach D. J Electrochem Soc, 2000, 147: 2486

[57] Chmiola J, Yushin G, Gogotsi Y, Portet C, Simon P, Taberna P L. Science, 2006, 313: 1760

[58] Seredych M, Koscinski M, Sliwinska-Bartkowiak M, Bandosz T J. ACS Sustainable Chem Eng, 2013, 1: 1024

[59] Gomez H, Ram M K, Alvi F, Villalba P, Stafanakos E, Kumar A. J Power Sources, 2011, 196: 4102

[60] Seredych M, Koscinski M, Sliwinska-Bartkowiak M, Bandosz T J. J Power Sources, 2012, 220: 243 